\title{
TITLE:
}

\section{Interactions of fragment ions of tetradecane with solid surfaces}

\section{AUTHOR(S):}

Takaoka, Gikan H.; Takeuchi, Mitsuaki; Ryuto, Hiromichi; Imanaka, Kousuke; Hayashi, Kyohei

\section{CITATION:}

Takaoka, Gikan H. ... [et al]. Interactions of fragment ions of tetradecane with solid surfaces. Nuclear Instruments and Methods in Physics Research Section B: Beam Interactions with Materials and Atoms 2014, 341: $48-52$

\section{ISSUE DATE:}

2014-12

URL:

http://hdl.handle.net/2433/192900

\section{RIGHT:}

(C) 2014 Elsevier B.V.; This is not the published version. Please cite only the published version.; この論文は出版社版でありません。引用の際に は出版社版をご確認ご利用ください。 


\title{
Interactions of fragment ions of tetradecane with solid surfaces
}

Gikan H. Takaoka*, Mitsuaki Takeuchi, Hiromichi Ryuto, Kousuke Imanaka and

Kyohei Hayashi

Photonics and Electronics Science and Engineering Center, Kyoto University

Katsura, Nishikyo-ku, Kyoto 615-8510, Japan

\begin{abstract}
The vapors of tetradecane $\left(\mathrm{C}_{14} \mathrm{H}_{30}\right)$ were ionized by an electron bombardment method. Fragment ions such as $\mathrm{C}_{3} \mathrm{H}_{7}, \mathrm{C}_{6} \mathrm{H}_{13}$ and $\mathrm{C}_{12} \mathrm{H}_{25}$ ions were separated by $\mathrm{E} \times \mathrm{B}$ filter (Wien filter), and accelerated toward the $\mathrm{Si}(100)$ substrates. Thickness measurement showed that thin films were deposited on the $\mathrm{Si}$ substrates by $\mathrm{C}_{3} \mathrm{H}_{7}$ and $\mathrm{C}_{6} \mathrm{H}_{13}$ ion irradiation, although $\mathrm{Si}$ substrate surface was sputtered by $\mathrm{C}_{12} \mathrm{H}_{25}$ ion irradiation. RBS measurement showed that the irradiation damage by the fragment ion beams decreased with increasing the molecular weight of fragment ions at the same acceleration voltage. Furthermore, Raman spectra as well as XPS measurement showed that DLC films were formed by $\mathrm{C}_{3} \mathrm{H}_{7}$ and $\mathrm{C}_{6} \mathrm{H}_{13}$ ion irradiation, and the film thickness was larger for $\mathrm{C}_{3} \mathrm{H}_{7}$ ion irradiation. On the contrary, for $\mathrm{C}_{12} \mathrm{H}_{25}$ ion irradiation, chemical sputtering was occurred by surface reaction of hydrogen and methyl radicals with silicon atoms. The chemical reaction on the irradiated substrate surface could be enhanced owing to higher temperatures, which were performed by high-density irradiation effect of the polyatomic ions.
\end{abstract}

Keywords: Polyatomic ion, Fragment ion, Mass separation, Surface interaction, Irradiation effect 


\section{Introduction}

Carbon materials have attracted much interest due to the variety of material properties such as diamond, graphite, fullerene, nanotube, and graphene. For example, graphene, which is a single sheet of graphite, exhibits the unique electron-transport and optical properties [1,2]. It has had a major impact on fundamental research in nanomaterials, and provided an excellent platform for exploring novel material properties and enhancing material performance [3]. Also, other carbon materials as well as graphene exhibit exceptional properties such as high melting point, high hardness, high wear, high chemical inertness, and excellent biocompatibility. For example, fullerenes and nanotubes, which form a curved structure of carbon atoms, tolerate high strain without collapsing. They are excellent candidates for advanced applications in electronics and photonics. In recent years, these carbon materials have been produced by using various kinds of material processing [4-8].

Ion beam technology is one example of ion-assisted material processing, and it has recently attracted much interest due to the controllability and variety of ion beams. For example, various kinds of ion beams such as atomic, molecular, and cluster ion beams, are available, and they are widely used in scientific and technological fields [9-12]. In these ion beams, a polyatomic molecular ion beam exhibits unique features, one of which is that it can transfer energy and mass as well as fragment radicals toward solid surfaces. These radicals play an important role in chemical erosion and sputtering of solid surfaces. Another feature is that impact of polyatomic ions on solid surfaces represent unique irradiation effects such as high density, multiple-collision and low energy irradiation effects [13-16]. For example, the high density irradiation effect enhances the surface temperature of the impact region $[17,18]$, which enhances the chemical reactions occurring on the surface. Based on these features, the polyatomic ion beams can be applied to the surface processes such as deposition, etching, shallow implantation, and mixing processes by adjusting the incident energy of polyatomic 
molecular ions and fragment ions.

Furthermore, for polyatomic molecular ion irradiation, the critical size is an important factor in the collision process. It is defined by the number of atoms consisting of a polyatomic molecular ion, impact of which changes from binary to multiple collisions. The analysis of the critical size has attracted much attention from the scientific point of view. In this paper, we focus on tetradecane $\left(\mathrm{C}_{14} \mathrm{H}_{30}\right)$ as a polyatomic molecule. In order to clarify the critical size, we produce various kinds of fragment ions such as $\mathrm{C}_{3} \mathrm{H}_{7}, \mathrm{C}_{6} \mathrm{H}_{13}$ and $\mathrm{C}_{12} \mathrm{H}_{25}$ ions. Also, we investigate the interactions of these fragment ions with Si (100) substrates. Furthermore, carbon material processing on the base of ion beam mixing, deposition, and sputtering, is demonstrated with the fragment ion beams.

\section{Experimental}

The details of the polyatomic ion beam system were described elsewhere [19,20]. Vapors of liquid materials such as normal tetradecane $\left(\mathrm{C}_{14} \mathrm{H}_{30}\right)$ were ejected into a vacuum chamber and entered the ionizer. The vapor pressure was kept at $1.0 \times 10^{-4}$ Torr. In the ionizer, vapors were ionized by electron bombardment. Electrons were emitted from a tungsten filament, and were accelerated by a voltage applied between the filament and the cylindrical anode. The diameter of the cylindrical anode was 20 $\mathrm{mm}$. In order to enhance the ionization efficiency, the mirror type of magnetic field was employed using a pair of samarium-cobalt permanent magnets, and the magnetic field along the central axis was adjusted to be at $10 \mathrm{mT}$. The electron voltage for ionization $\left(V_{\mathrm{e}}\right)$ was adjusted to be between $0 \mathrm{~V}$ and $300 \mathrm{~V}$, and the electron current for ionization (Ie) was adjusted to be between $0 \mathrm{~mA}$ and $100 \mathrm{~mA}$. Several fragment ions were produced by dissociative ionization, and extracted by applying an extraction voltage to the extraction electrode. The extraction voltage $\left(V_{\text {ext }}\right)$ was adjusted to be between $0 \mathrm{kV}$ and $5 \mathrm{kV}$. 
The extracted ions were mass-separated by an $\mathrm{E} \times \mathrm{B}$ filter (Wien filter), in which ion beam axis, electric field (E) and magnetic field (B) were all mutually perpendicular. The magnetic field was obtained using a cuboid neodymium (Nd) permanent magnet with a surface size of $50 \mathrm{~mm} \times 50 \mathrm{~mm}$. The magnetic field measured near the surface was $390 \mathrm{mT}$. The mass-separated ion beams by adjusting the electric field in the $\mathrm{E} \times \mathrm{B}$ filter were accelerated toward a substrate, which was set on a substrate holder. The acceleration voltage $\left(V_{\mathrm{a}}\right)$ was adjusted to be between $1 \mathrm{kV}$ and $10 \mathrm{kV}$. The substrates used were $\mathrm{Si}(100)$. The fluence to the substrates was determined based on the ion current. When the desired fluence was attained, the shutter was closed to terminate ion irradiation. The background pressure around the substrate was $8.0 \times 10^{-7}$ Torr, which was attained using a turbo molecular pump.

\section{Results and discussion}

\subsection{Ion beam characteristics}

The electron bombardment method produced many fragment ions of a polyatomic molecule. Figure 1 shows the mass spectrum of tetradecane ion beams. The extraction voltage $\left(V_{\text {ext }}\right)$ was $3.0 \mathrm{kV}$, and the electron voltage for ionization $\left(V_{\mathrm{e}}\right)$ was $150 \mathrm{~V}$. Also, the electron current for ionization $\left(I_{\mathrm{e}}\right)$ was $25 \mathrm{~mA}$, and the magnetic field was $10 \mathrm{mT}$. As shown in the figure, $\mathrm{C}_{n} \mathrm{H}_{2 n+1}$ ions $(\mathrm{n}=1-14)$ are produced, although the mass resolution is not sufficient for the large-mass fragment ions. The mass number of the highest peak is 57 , which corresponds to $\mathrm{C}_{4} \mathrm{H}_{9}$ ion. The second highest peak corresponds to $\mathrm{C}_{3} \mathrm{H}_{7}$ ion with a mass number of 43 . Also, a small peak of $\mathrm{C}_{12} \mathrm{H}_{25}$ ion is obtained. Compared with the ion current without applying the magnetic field, the ion current extracted was approximately ten times larger, and it was approximately $55 \mu \mathrm{A}$. Also, higher mass fragment ions such as $\mathrm{C}_{12} \mathrm{H}_{25}$ ion increased, because the low-energy electrons for ionization were effectively confined by using the magnetic fields. 


\subsection{Irradiation effect}

The irradiation damage by tetradecane ion beams was investigated by using Rutherford backscattering spectroscopy (RBS) channeling method. The probe beam was $\mathrm{He}^{+}$ion beam with the energy of $2.0 \mathrm{MeV}$. The scattering angle was 165 degrees. Figure 2 shows the RBS channeling spectra for the $\mathrm{Si}(100)$ surfaces irradiated by $\mathrm{C}_{3} \mathrm{H}_{7}$ and $\mathrm{C}_{12} \mathrm{H}_{25}$ ions. The acceleration voltage $\left(V_{\mathrm{a}}\right)$ was $6.0 \mathrm{kV}$, and fluence was $4.0 \times 10^{16}$ carbons $/ \mathrm{cm}^{2}$. As shown in the figure, the surface peak for unirradiated Si-surface is small. It was a few \%, which was estimated from the ratio of channeling and random spectra. Also, the Si surface peak for the $\mathrm{C}_{12} \mathrm{H}_{25}$ ion irradiation is smaller than that for the $\mathrm{C}_{3} \mathrm{H}_{7}$ ion irradiation. This indicates that the irradiation damage by $\mathrm{C}_{12} \mathrm{H}_{25}$ ions is less than that by $\mathrm{C}_{3} \mathrm{H}_{7}$ ions. From the area of Si surface peaks, the number of displaced atoms was estimated by using the values such as the density of bulk $\mathrm{Si}$, the ratio of aligned and random spectra for surface peak, the energy per channel measured.

Figure 3 shows the number of displaced atoms for the Si(100) surfaces irradiated by fragment ions such as $\mathrm{C}_{3} \mathrm{H}_{7}, \mathrm{C}_{6} \mathrm{H}_{13}$ and $\mathrm{C}_{12} \mathrm{H}_{25}$ ions. The acceleration voltage $\left(V_{\mathrm{a}}\right)$ was $6.0 \mathrm{kV}$, and fluence was $4.0 \times 10^{16}$ carbons $/ \mathrm{cm}^{2}$. The standard error was estimated to be $\pm 6 \%$. As shown in the figure, the number of displaced atoms decreases with increasing the molecular weight of the fragment ions. By assuming that the fragment ions are broken up into atoms after impact on the surface, the incident energy of a carbon atom in the fragment ion can be estimated. According to a rough estimation that the incident energy of hydrogen atoms might be neglected, it could be the accelerating energy divided by the number of carbon atoms. For example, it is $0.5 \mathrm{keV}$ per carbon atom for $\mathrm{C}_{12} \mathrm{H}_{25}$ ion irradiation, which is much less than that of $\mathrm{C}_{3} \mathrm{H}_{7}$ and $\mathrm{C}_{6} \mathrm{H}_{13}$ ions. Therefore, the irradiation damage is less for $\mathrm{C}_{12} \mathrm{H}_{25}$ ion irradiation due to the low energy irradiation effect.

Figure 4 shows the number of displaced atoms for the $\mathrm{Si}(100)$ surfaces irradiated at an incident energy of approximately $0.5 \mathrm{keV}$ per carbon atom by $\mathrm{C}_{3} \mathrm{H}_{7}, \mathrm{C}_{6} \mathrm{H}_{13}$ and 
$\mathrm{C}_{12} \mathrm{H}_{25}$ ions. The acceleration voltage for $\mathrm{C}_{3} \mathrm{H}_{7}, \mathrm{C}_{6} \mathrm{H}_{13}$ and $\mathrm{C}_{12} \mathrm{H}_{25}$ ions was $1.5 \mathrm{kV}, 3.0$ $\mathrm{kV}$, and $6.0 \mathrm{kV}$, respectively. Fluence was $4.0 \times 10^{16}$ carbons $/ \mathrm{cm}^{2}$. As shown in the figure, the number of displaced atoms is similar for $\mathrm{C}_{6} \mathrm{H}_{13}$ and $\mathrm{C}_{12} \mathrm{H}_{25}$ ion irradiation, because the incident energy of a carbon atom in the fragment ions is almost the same, i.e. approximately $0.5 \mathrm{keV}$. However, the irradiation damage by $\mathrm{C}_{3} \mathrm{H}_{7}$ ion irradiation is smaller than that by $\mathrm{C}_{6} \mathrm{H}_{13}$ and $\mathrm{C}_{12} \mathrm{H}_{25}$ ion irradiation. This is due to the formation of carbon layers with the thickness larger than a few nm (See Figure 5.). The carbon layers formed stopped the ion irradiation on the Si surface, which resulted in the decrease of the fluence. In addition, taking account of hydrogen atoms, a hydrogen atom in the fragment ions had the incident energy of approximately $35 \mathrm{eV}$. In this case, the total incident energy deposited on the $\mathrm{Si}$ surface by the hydrogen atoms is $245 \mathrm{eV}$ and $875 \mathrm{eV}$ for the $\mathrm{C}_{3} \mathrm{H}_{7}$ and $\mathrm{C}_{12} \mathrm{H}_{25}$ ion irradiation, respectively. Therefore, the thermal spike and the chemical erosion by the high energy density irradiation as well as the multiple collisions might be enhanced by $\mathrm{C}_{12} \mathrm{H}_{25}$ ion irradiation, which results in the increase of the irradiation damage compared with the $\mathrm{C}_{3} \mathrm{H}_{7}$ ion irradiation.

Figure 5 shows the thickness of $\mathrm{Si}(100)$ surfaces irradiated at different incident energies for a carbon atom of $\mathrm{C}_{3} \mathrm{H}_{7}, \mathrm{C}_{6} \mathrm{H}_{13}$ and $\mathrm{C}_{12} \mathrm{H}_{25}$ ions. The thickness, which is determined by the step difference between the unirradiated and irradiated surface, was measured using the high resolution surface profiler XP-2 (Ambios Technology, Inc.). Positive thickness was the film thickness, and negative one was the sputter depth. The acceleration voltage was adjusted to be between $0.75 \mathrm{kV}$ and $9 \mathrm{kV}$. Fluence was $4.0 \times$ $10^{16}$ carbons $/ \mathrm{cm}^{2}$. As shown in the figure, for $\mathrm{C}_{3} \mathrm{H}_{7}$ ion irradiation, the thickness increases with increasing the acceleration voltage. Then, it decreases at an acceleration voltage of $9 \mathrm{kV}$, which corresponds to the incident energy of $2.51 \mathrm{keV}$ per carbon atom and $0.21 \mathrm{keV}$ per hydrogen atom, respectively. This indicates that carbon layers are formed by ion beam mixing and deposition, although the physical sputtering of $\mathrm{Si}$ surfaces occurs at an acceleration voltage of $9 \mathrm{kV}$. Also, for $\mathrm{C}_{6} \mathrm{H}_{13}$ ion irradiation, 
carbon layers are formed. However, the thickness is smaller than that for $\mathrm{C}_{3} \mathrm{H}_{7}$ ion irradiation. This might be ascribed to the chemical sputtering of Si surfaces with hydrogen atoms included in the $\mathrm{C}_{6} \mathrm{H}_{13}$ ion. On the other hand, for $\mathrm{C}_{12} \mathrm{H}_{25}$ ion irradiation, the sputtering occurs. In addition, the surface roughness measured by an atomic force microscope (AFM) was similar to that of the unirradiated Si surface, i.e. $0.12 \mathrm{~nm}$. The Si surface irradiated by $\mathrm{C}_{12} \mathrm{H}_{25}$ ions was flat at an atomic level, even if it was sputtered. Raman spectra were measured for the $\operatorname{Si}(100)$ surfaces irradiated at different acceleration voltages by $\mathrm{C}_{3} \mathrm{H}_{7}$ and $\mathrm{C}_{12} \mathrm{H}_{25}$ ions. The acceleration voltage was adjusted to be between $1.5 \mathrm{kV}$ and $9.0 \mathrm{kV}$. Fluence was $4.0 \times 10^{16}$ carbons $/ \mathrm{cm}^{2}$. As shown in Figure 6, D and $\mathrm{G}$ band peaks appear at the wave numbers of approximately $1300 \mathrm{~cm}^{-1}$ and $1500 \mathrm{~cm}^{-1}$, respectively. These are typical ones for diamond like carbon (DLC) films, although they are weak for $\mathrm{C}_{12} \mathrm{H}_{25}$ ion irradiation at an acceleration voltage of $9.0 \mathrm{kV}$. The peak ratio of $\mathrm{D}$ and $\mathrm{G}$ bands, which is expressed by $\mathrm{I}_{\mathrm{D}} / \mathrm{I}_{\mathrm{G}}$, can be estimated from the curve areas fitted in the figure, and it is larger for $\mathrm{C}_{3} \mathrm{H}_{7}$ ion irradiation than that for $\mathrm{C}_{12} \mathrm{H}_{25}$ ion irradiation. This indicates that more amount of $\mathrm{SP}^{2}$ fractions are contained in $\mathrm{C}_{3} \mathrm{H}_{7}$ ion irradiated surfaces [21,22].

Furthermore, the amount of hydrogen atoms included in the DLC films can be estimated from the G band peak intensity (S) with respect to the background signal intensity $(\mathrm{N})$, which is expressed by $\mathrm{N} /(\mathrm{S}+\mathrm{N})$ [23]. If the ratio is large, more hydrogen atoms are contained in the films. According to the estimation, the DLC thin layer formed by $\mathrm{C}_{12} \mathrm{H}_{25}$ ion irradiation contains more hydrogen atoms than that by $\mathrm{C}_{3} \mathrm{H}_{7}$ ion irradiation. It should be noted that $\mathrm{C}_{12} \mathrm{H}_{25}$ ions are dissociated after irradiation, and some fragments such as methyl radicals are produced. These radicals have another important role in chemical sputtering of Si surfaces as well as DLC layer formation. Therefore, DLC layers formed by $\mathrm{C}_{12} \mathrm{H}_{25}$ ion beams are thinner, and contain the hydrogen atoms. 
XPS measurement was performed for substrate surfaces after etching. The etching time by argon ion beam sputtering was 5 sec. Figure 7 shows the C1s peaks for $\operatorname{Si}(100)$ surfaces irradiated by (a) $\mathrm{C}_{3} \mathrm{H}_{7}$ and (b) $\mathrm{C}_{12} \mathrm{H}_{25}$ ions. The acceleration voltage was adjusted to be between $1.5 \mathrm{kV}$ and $9.0 \mathrm{kV}$. Fluence was $4.0 \times 10^{16}$ carbons $/ \mathrm{cm}^{2}$. As shown in Figs. $7(\mathrm{a})$, the $\mathrm{C}_{1 \mathrm{~s}}$ peak intensity for $\mathrm{C}_{3} \mathrm{H}_{7}$ ion irradiation is similar at the acceleration voltages of $1.5 \mathrm{kV}$ and $6.0 \mathrm{kV}$. Because the implanted depth of carbon atoms is smaller than the XPS detection depth, that is $5 \mathrm{~nm}$, the total amount of carbon atoms measured corresponds to the fluence. Also, as shown in the figure, the graphite carbons as well as $\mathrm{C}-\mathrm{C}$ and $\mathrm{C}-\mathrm{H}$ bond carbons are contained, although the contamination of residual oxygen gas occurs in the DLC films deposited. On the other hand, as shown in Fig. $7(\mathrm{~b})$, the $\mathrm{C}_{1 \mathrm{~s}}$ peak intensity for $\mathrm{C}_{12} \mathrm{H}_{25}$ ion irradiation is smaller at $V_{\mathrm{a}}=9 \mathrm{kV}$ compared with that at $V_{\mathrm{a}}=6 \mathrm{kV}$. This is ascribed to the enhancement of the chemical sputtering, which increases with increasing the acceleration voltage. Methyl radicals as well as hydrogen atoms might be employed for the chemical sputtering of Si substrate surfaces (See Figure 8.). As a result, the amount of carbon atoms remained on the surface decreases with increasing the acceleration voltage. Furthermore, another peak corresponding to a $\mathrm{SiC}$ bond appears at a binding energy of $283.3 \mathrm{eV}$. The chemical reaction between $\mathrm{C}_{12} \mathrm{H}_{25}$ ions and $\mathrm{Si}$ atoms occurs on the irradiated surface, which results in the $\mathrm{SiC}$ formation.

In order to confirm the chemical reaction between methyl radicals and $\mathrm{Si}$ atoms, the Si2p peaks were measured. The etching time was set at $400 \mathrm{sec}$ for decreasing the carbon over-layer thickness. Figure 8 shows the Si2p peaks for $\mathrm{Si}(100)$ surfaces irradiated by (a) $\mathrm{C}_{3} \mathrm{H}_{7}$ and (b) $\mathrm{C}_{12} \mathrm{H}_{25}$ ions. The acceleration voltage was adjusted to be at $1.5 \mathrm{kV}$ for $\mathrm{C}_{3} \mathrm{H}_{7}$ ion irradiation and $6.0 \mathrm{kV}$ for $\mathrm{C}_{12} \mathrm{H}_{25}$ ion irradiation, respectively. Fluence was $4.0 \times 10^{16}$ carbons $/ \mathrm{cm}^{2}$. As shown in the figure, the $\mathrm{C}_{1 \mathrm{~s}}$ peak for $\mathrm{C}_{3} \mathrm{H}_{7}$ ion irradiation consists of mainly $\mathrm{Si}$ and $\mathrm{SiC}$. In addition to these peaks, for $\mathrm{C}_{12} \mathrm{H}_{25}$ ion irradiation, another peak corresponding to $\mathrm{Si}\left(\mathrm{CH}_{\mathrm{x}}\right)_{\mathrm{y}}$ appears, which indicates that the 
volatile product, for example $\mathrm{Si}\left(\mathrm{CH}_{3}\right)_{4}$, remained on the $\mathrm{Si}$ surface after the $\mathrm{C}_{12} \mathrm{H}_{25}$ ion irradiation. With regard to the chemical sputtering by $\mathrm{C}_{12} \mathrm{H}_{25}$ ions, hydrogen atoms as well as methyl radicals play an important role. The number of hydrogen atoms included in $\mathrm{C}_{12} \mathrm{H}_{25}$ ion is larger compared with $\mathrm{C}_{3} \mathrm{H}_{7}$ ion. Therefore, the chemical sputtering occur as an evaporation of volatile materials such as silicon hydride and silicon organic materials. Furthermore, the chemical reaction between silicon atoms and fragment ions increases with increasing the surface temperature, which is achieved by the high density irradiation effect and the multiple collision effect of $\mathrm{C}_{12} \mathrm{H}_{25}$ ions. These effects are not achieved by the binary collision cascade of atomic ions as well as by the irradiation of small fragment ions such as $\mathrm{C}_{3} \mathrm{H}_{7}$ and $\mathrm{C}_{6} \mathrm{H}_{13}$ ions. The critical size of the fragment ions could be defined by the number of carbon atoms included, which represent multiple collisions rather than binary collisions. Therefore, the fragment ion with the critical size exists between $\mathrm{C}_{6} \mathrm{H}_{13}$ ion and $\mathrm{C}_{12} \mathrm{H}_{25}$ ion, and it could be approximately 10 carbon atoms.

\section{Conclusions}

The vapors of tetradecane $\left(\mathrm{C}_{14} \mathrm{H}_{30}\right)$ were ionized by an electron bombardment method, and fragment ions such as $\mathrm{C}_{3} \mathrm{H}_{7}, \mathrm{C}_{6} \mathrm{H}_{13}$ and $\mathrm{C}_{12} \mathrm{H}_{25}$ ions were produced. The fragment ions were separated by $\mathrm{E} \times \mathrm{B}$ filter, and accelerated toward the $\mathrm{Si}(100)$ substrates. The acceleration voltage was adjusted to be between $1 \mathrm{kV}$ and $10 \mathrm{kV}$, and fluence was $4.0 \times 10^{16}$ carbons $/ \mathrm{cm}^{2}$. Thickness measurement showed that carbon thin films were formed on the $\mathrm{Si}$ substrates by $\mathrm{C}_{3} \mathrm{H}_{7}$ and $\mathrm{C}_{6} \mathrm{H}_{13}$ ion irradiation, although $\mathrm{Si}$ substrate surface was sputtered by $\mathrm{C}_{12} \mathrm{H}_{25}$ ion irradiation. For the $\mathrm{C}_{12} \mathrm{H}_{25}$ ion irradiation, the chemical sputtering of Si surfaces by hydrogen atoms as well as methyl radicals might be occurred, because the surface temperature of impact region was enhanced due to the high density irradiation effect of the polyatomic ions. Also, RBS measurement showed that $\mathrm{C}_{12} \mathrm{H}_{25}$ ion irradiation damage at the same acceleration 
voltage was lower than $\mathrm{C}_{3} \mathrm{H}_{7}$ and $\mathrm{C}_{6} \mathrm{H}_{13}$ ion irradiations, and low energy irradiation effect was performed by the polyatomic ion irradiation. Furthermore, according to Raman spectra as well as XPS measurement, DLC films were formed on the Si substrates, and the film thickness for $\mathrm{C}_{3} \mathrm{H}_{7}$ ion irradiation was larger than that for $\mathrm{C}_{6} \mathrm{H}_{13}$ ion irradiation. Thus, the polyatomic ions such as fragment ions of tetradecane exhibited unique irradiation effects, and they were different depending on the mass number corresponding to the number of carbon atoms. In addition, DLC film formation at room temperature as well as $\mathrm{Si}$ surface etching with lower irradiation damage was demonstrated with the fragment ion beams by controlling the incident energy.

\section{Acknowledgements}

The authors are grateful to the Quantum Science and Engineering Center of Kyoto University for the RBS measurement. Also, we are grateful to Prof. T. Kuji in Tokai University for Raman Spectroscopy measurement. 


\section{References}

[1]K.S. Novoselov, A.K. Geim, S.V. Morozov, D. Jiang, Y. Zhang, S.V. Dubonos, I.V. Grigorieva, and A.A. Frisov, Science 306 (2004) 666.

[2]A.K. Geim and K.S. Novoselov, Nat. Mater. 6 (2007) 183.

[3] W. Lu,P. Soukiassian, and J. Boeckl, MRS Bull. 37 (2012) 1119.

[4] H.W. Kroto, J.R. Heath, S.C. Obrien, R.F. Curl, and R.E. Smalley, Nature 318 (1985) 162.

[5] S. Iijima, Nature 354 (1991) 56.

[6] B.Kitiyanan, W.E. Alvarez, J.H. Harwell, and D.E. Resasco, Chem. Phys. Lett. 317 (2000) 497.

[7] J. Ishikawa, Surf. Coat. Technol. 65 (1994) 64.

[8] F.Z. Cui and D.J. Li, Surf. Coat. Technol. 131 (2000) 481.

[9] H. Haberland: “Clusters of Atoms and Molecules” (Springer-Verlag, Berlin, 1994)

[10] H. Yasumatsu and T. Kondow, Rep. Prog. Phys. 66 (2003) 1783.

[11] D.J. Stokes, L. Roussel, O. Wilhelmi, L.A. Giannuzzi and D. HW Hubert, Mater. Res. Soc. Proc. 1020 (2007) p.15.

[12] J. Ishikawa, Rev. Sci. Instrum. 79 (2008) 02 C506.

[13] K. Goto, J. Matsuo, T. Seki, H. Hinakata, I. Yamada, and T. Hisatsugu, IEDM Tech. Dig. (1996) 435.

[14] Z. Herman, Int. J. Mass Spectro. 233 (2004) 361.

[15] N.G. Rudawski, L.R. Whidden, V. Craciun, and K.S. Jones, J. Electro. Mater. 38 (2009) 1926.

[16] G.H. Takaoka, H. Ryuto, and M. Takeuchi, J. Mater. Res. 27 (2012) 806.

[17] Z. Insepov, M. Sosnowski, G.H. Takaoka and I. Yamada: Mater. Res. Soc. Proc. 316, (1994) p.999. 
[18] Z. Insepov and I. Yamada, Surf. Rev. Lett. 3, 1023 (1996).

[19] G.H. Takaoka, M. Takeuchi, and H. Ryuto, Rev. Sci. Instrum. 81 (2010) $02 B 302$.

[20] M. Takeuchi, H. Ryuto, and G.H. Takaoka, Proc. of IPAC'10, Kyoto, Japan (2010) p.136.

[21] T. Mikami, H. Nakazawa, M. Kudo and M. Mashita, Thin Solid Films 488 (2005) 87.

[22] A. Ferrari and C. Robertson, Phys. Rev. B61 (2000) 14095.

[23] K. Miura and M. Nakamura, J. Surf. Finish. Soc. of Japan 59 (2008) 51, in Japanese. 


\section{Figure captions}

Figure 1: Mass spectrum of tetradecane ion beams. The extraction voltage was $3 \mathrm{kV}$, and the electron voltage for ionization was $150 \mathrm{~V}$.

Figure 2: RBS channeling spectra for the $\mathrm{Si}(100)$ surfaces irradiated by $\mathrm{C}_{3} \mathrm{H}_{7}$ and $\mathrm{C}_{12} \mathrm{H}_{25}$ ions. The acceleration voltage $\left(V_{\mathrm{a}}\right)$ was $6.0 \mathrm{kV}$, and fluence was 4.0 $\times 10^{16}$ carbons $/ \mathrm{cm}^{2}$.

Figure 3: Number of displaced atoms for the Si(100) surfaces irradiated by fragment ions such as $\mathrm{C}_{3} \mathrm{H}_{7}, \mathrm{C}_{6} \mathrm{H}_{13}$ and $\mathrm{C}_{12} \mathrm{H}_{25}$ ions. The acceleration voltage was 6.0 $\mathrm{kV}$, and the fluence was $4.0 \times 10^{16}$ carbons $/ \mathrm{cm}^{2}$.

Figure 4: Number of displaced atoms for the $\mathrm{Si}(100)$ surfaces irradiated at an incident energy of approximately $0.5 \mathrm{keV}$ per carbon atom by $\mathrm{C}_{3} \mathrm{H}_{7}, \mathrm{C}_{6} \mathrm{H}_{13}$ and $\mathrm{C}_{12} \mathrm{H}_{25}$ ions. Fluence was $4.0 \times 10^{16}$ carbons $/ \mathrm{cm}^{2}$.

Figure 5: Thickness of Si(100) surface irradiated at different incident energies for a carbon atom of $\mathrm{C}_{3} \mathrm{H}_{7}, \mathrm{C}_{6} \mathrm{H}_{13}$ and $\mathrm{C}_{12} \mathrm{H}_{25}$ ions. Fluence was $4.0 \times 10^{16}$ carbons $/ \mathrm{cm}^{2}$.

Figure 6: Raman spectra for $\mathrm{Si}(100)$ surfaces irradiated at different acceleration voltages by (a) $\mathrm{C}_{3} \mathrm{H}_{7}$ and (b) $\mathrm{C}_{12} \mathrm{H}_{25}$ ions. Fluence was 4.0 x $10^{16}$ carbons $/ \mathrm{cm}^{2}$.

Figure 7: C1s peaks for $\mathrm{Si}(100)$ surfaces irradiated by (a) $\mathrm{C}_{3} \mathrm{H}_{7}$ and (b) $\mathrm{C}_{12} \mathrm{H}_{25}$ ions. Fluence was $4.0 \times 10^{16}$ carbons $/ \mathrm{cm}^{2}$. 
Figure 8: Si2p peaks for $\mathrm{Si}(100)$ surfaces irradiated by (a) $\mathrm{C}_{3} \mathrm{H}_{7}$ and (b) $\mathrm{C}_{12} \mathrm{H}_{25}$ ions.

Fluence was $4.0 \times 10^{16}$ carbons $/ \mathrm{cm}^{2}$. 


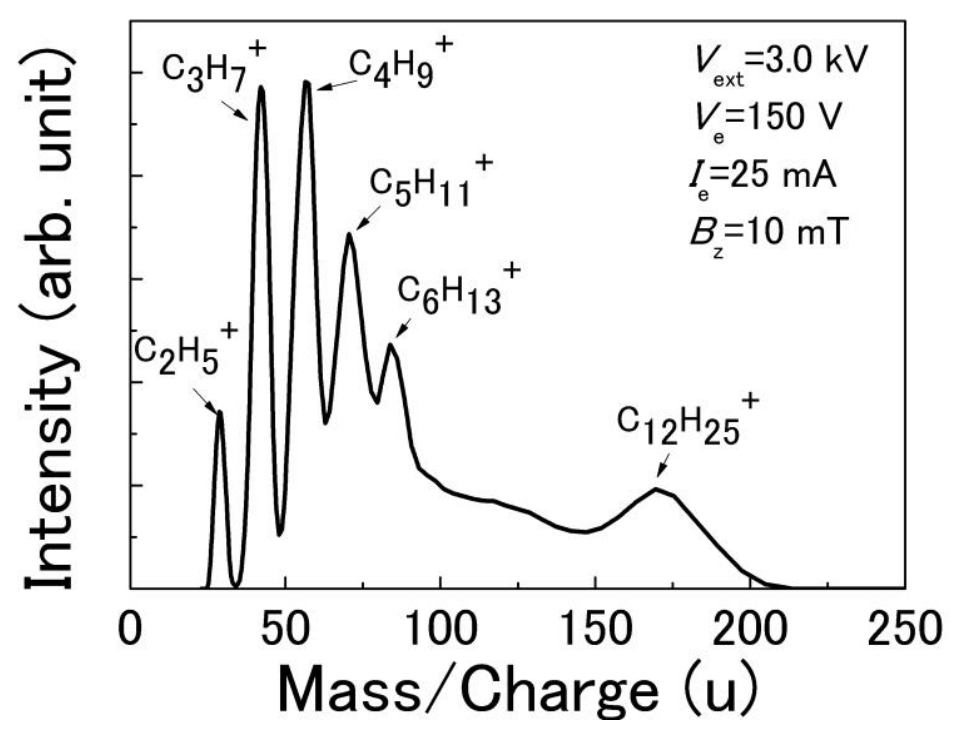

Figure 1: Takaoka et al. 


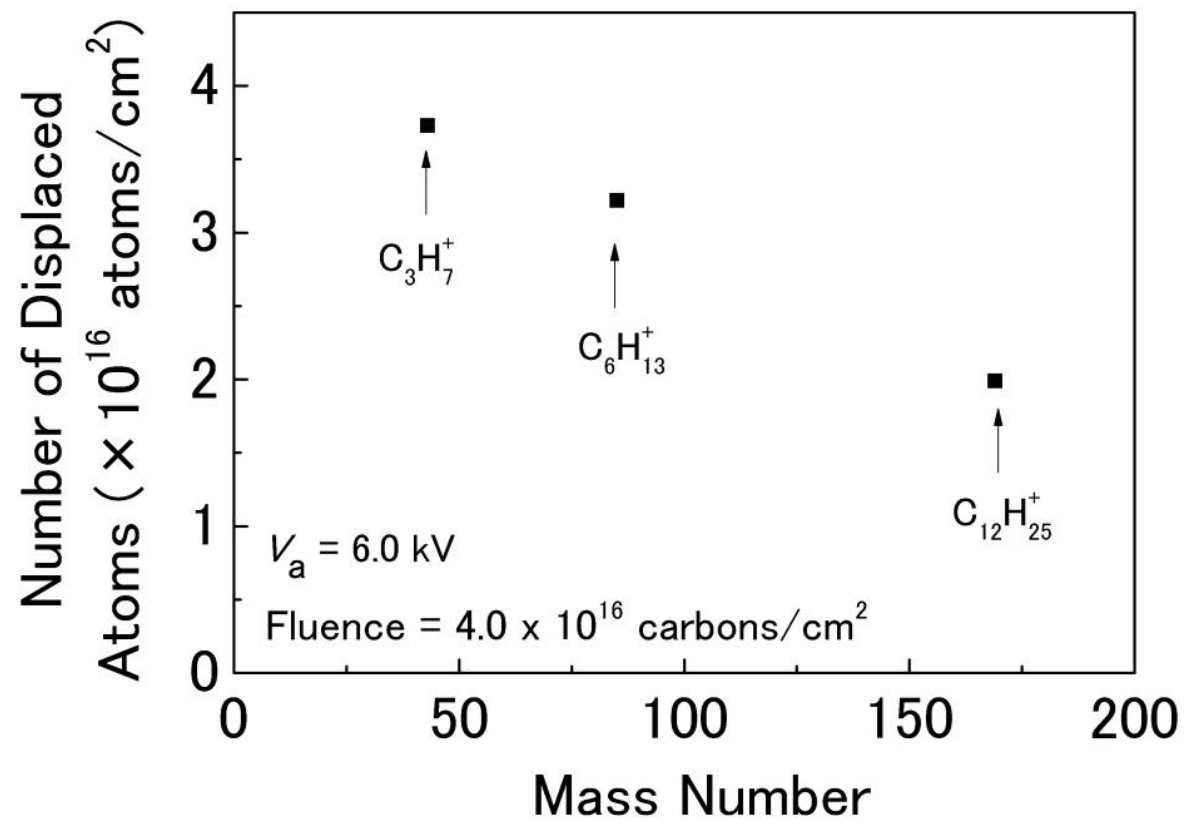

Figure 2: Takaoka et al. 


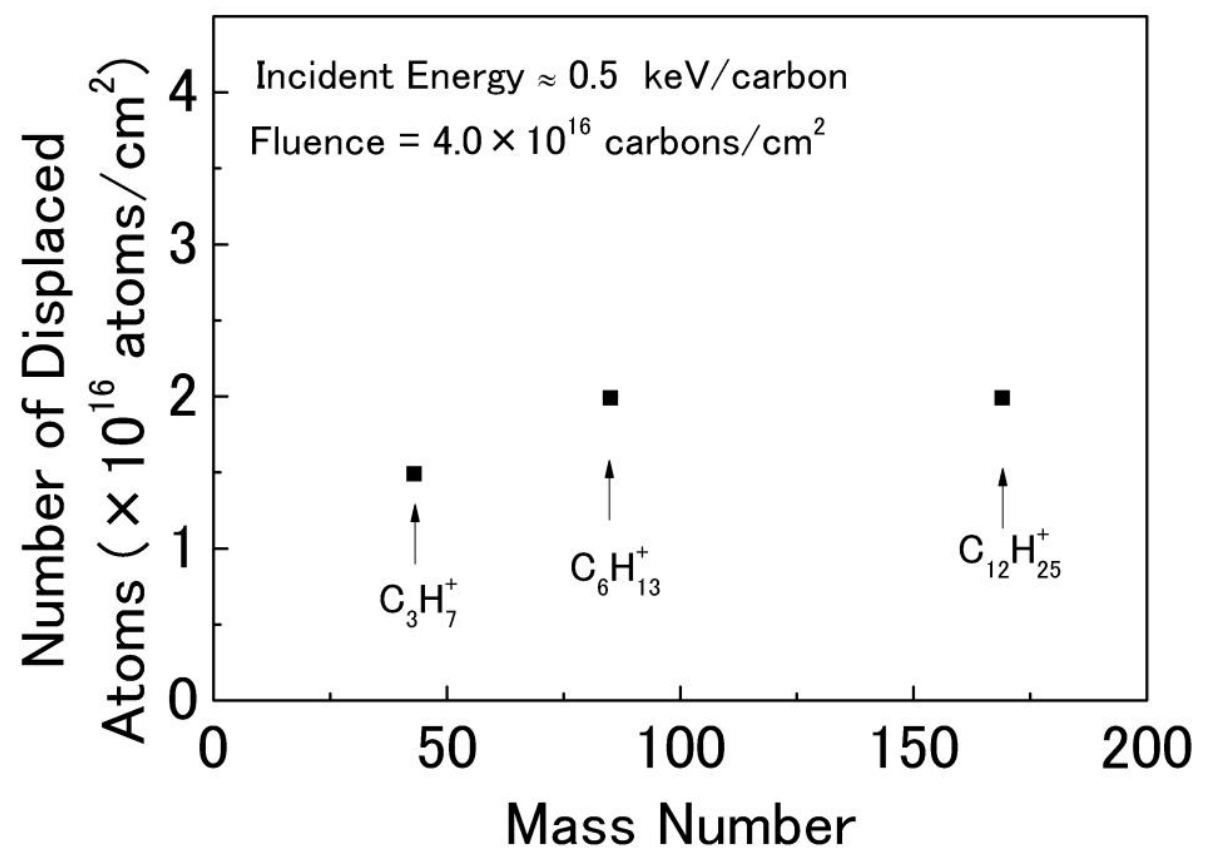

Figure 3: Takaoka et al. 


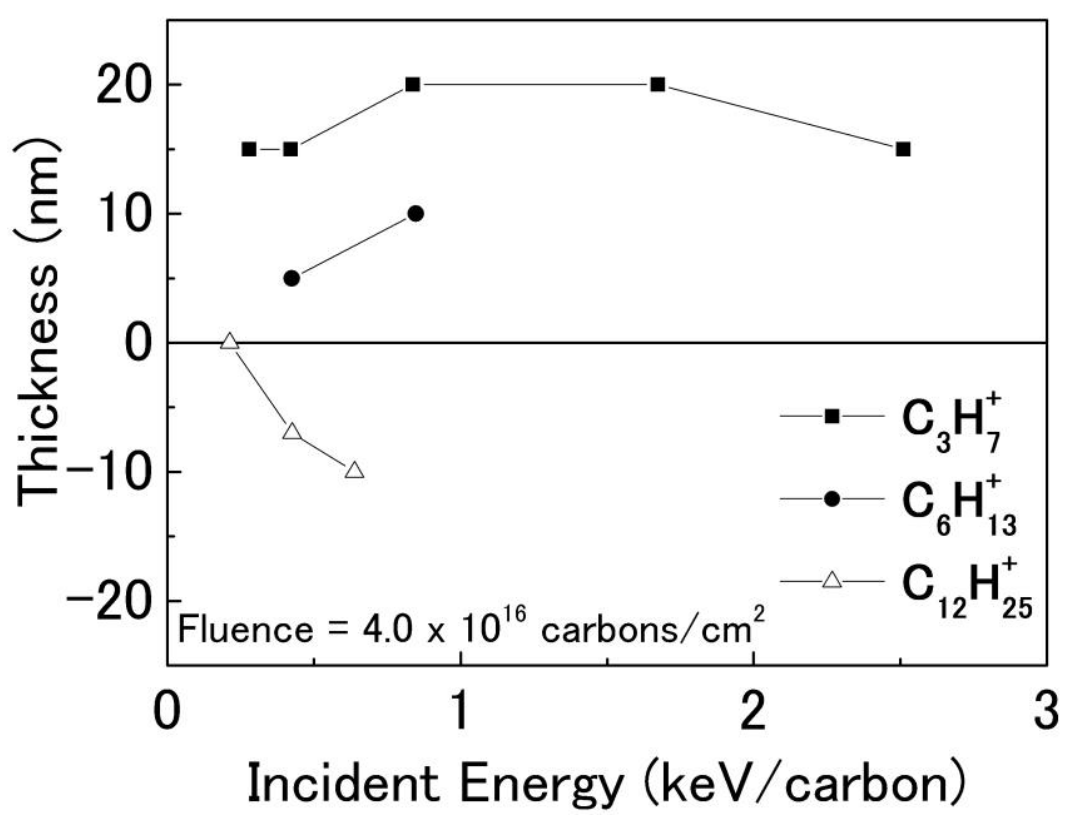

Figure 4: Takaoka et al. 

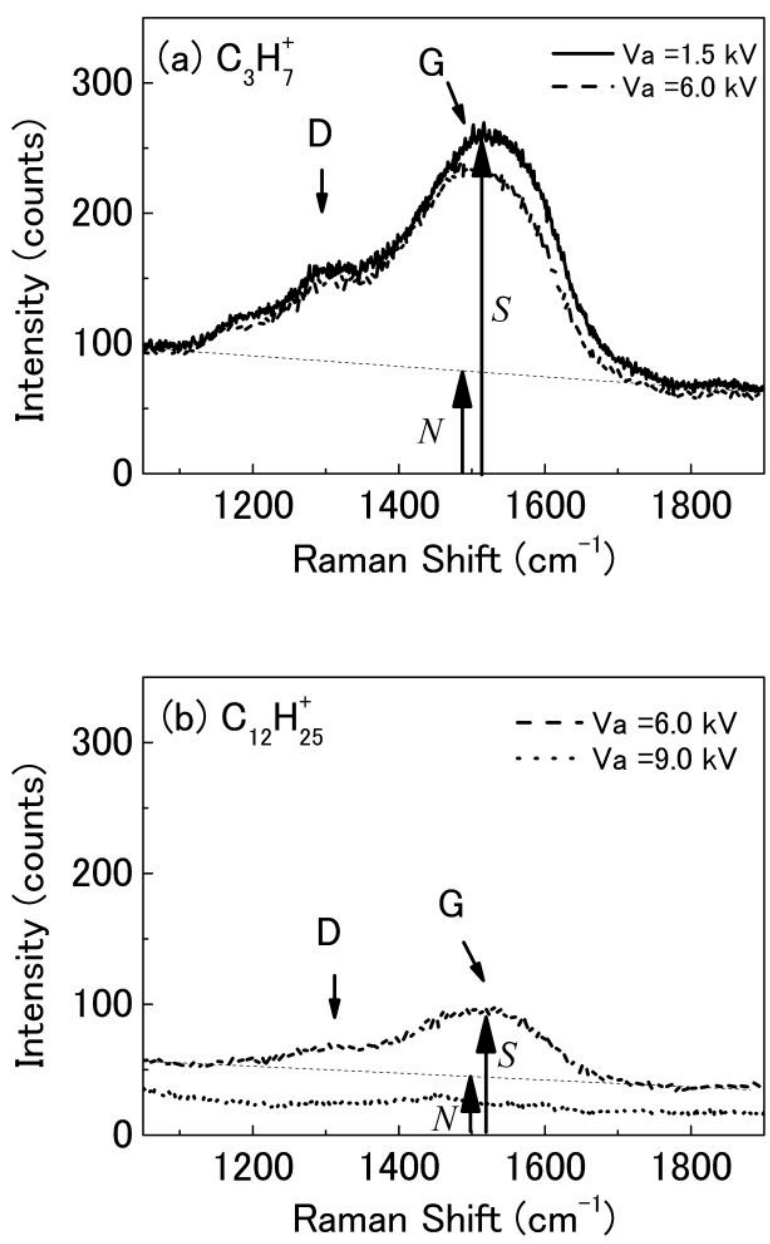

Figure 5: Takaoka et al. 
(a) $\mathrm{C}_{3} \mathrm{H}_{7}^{+} \quad$ Fluence $=4.0 \times 10^{16}$ carbons $/ \mathrm{cm}^{2}$

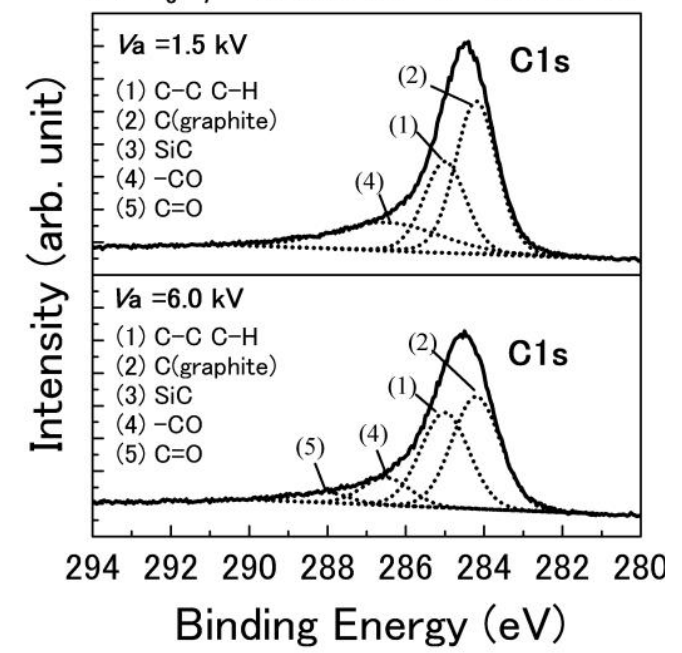

(b) $\mathrm{C}_{12} \mathrm{H}_{25}^{+}$Fluence $=4.0 \times 10^{16}$ carbons $/ \mathrm{cm}^{2}$

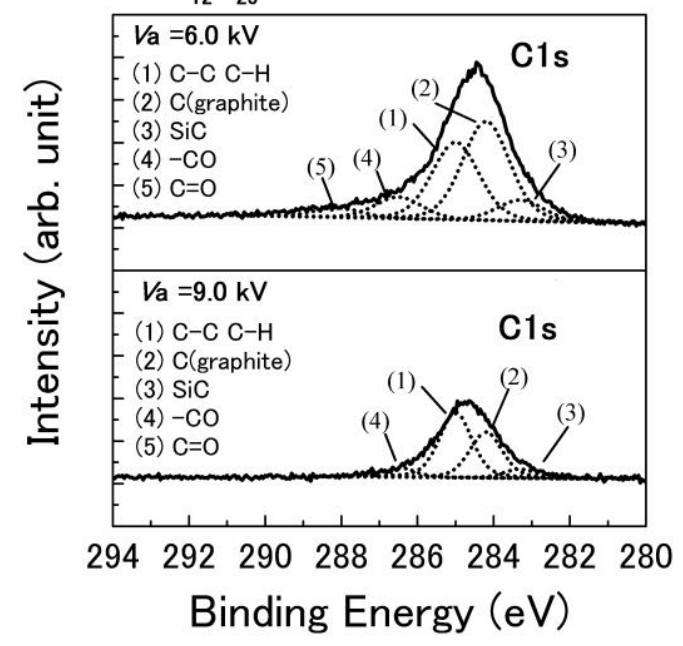

Figure 6: Takaoka et al. 